\title{
ALPHA RADIOLYSIS RESEARCH FY14
}

\author{
Stephen P. Mezyk
}

September 2014

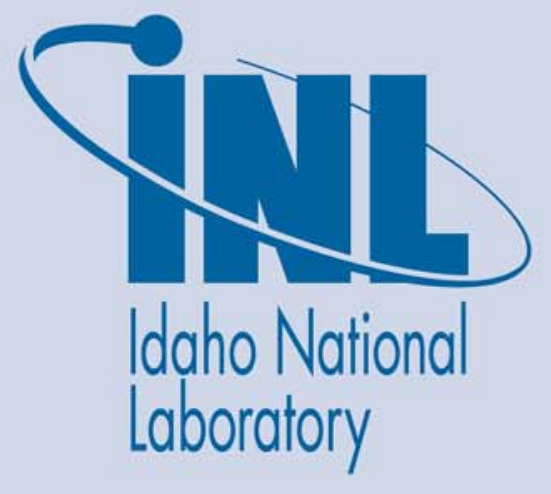

The INL is a U.S. Department of Energy National Laboratory operated by Battelle Energy Alliance 
INL/EXT-15-35428

\title{
ALPHA RADIOLYSIS RESEARCH FY14
}

Stephen P. Mezyk

September 2015

\section{Idaho National Laboratory \\ Idaho Falls, Idaho 83415}

http://www.inl.gov

\author{
Prepared for the \\ U.S. Department of Energy \\ Office of Nuclear Energy \\ Under DOE Idaho Operations Office \\ Contract DE-AC07-05ID14517
}




\section{Bruce Mincher milestone report}

\section{Alpha Radiolysis Research FY14}

\section{Received from prof. Steve Mezyk, Sept 2, 2014}

To obtain a full understanding of the overall radiation chemistry involved in large-scale Ln(III)An(III) separation processes, the impacts of both gamma and alpha radiolysis on the radicalinduced ligand degradations for both free and metal-complexed species have to be quantitatively determined. In this reporting period, we have continued our alpha-radiolysis studies into various ligand-solvent systems. These experimental measurements are difficult to perform, with no single reported method being optimal. Therefore, studies have been conducted using three concomitant approaches: internal isotope studies, ion-beam measurements and neutron-induced alpha decays in a TRIGA rector.

The initial system studied this year by alpha radiolysis was 0.10 M CMPO (octylphenyl-N,Ndiisobutylcarbamoylmethylphosphine oxide) in dodecane. Post irradiated samples were analyzed for the radiolytically-induced decrease in CMPO concentration (by HPLC), the appearance of degradation products (MS) and their Am solvent extraction distribution ratios. Results for the He ion-beam irradiation for both aerated and de-aerated solutions showed no CMPO loss up to a maximum absorbed dose of $50 \mathrm{kGy}$. Contact with $3.0 \mathrm{M} \mathrm{HNO}_{3}$ prior to irradiation showed similar results. However, for higher doses, obtained by either ${ }^{244} \mathrm{Cm}$ irradiation or using the TRIGA reactor, the results differed. No CMPO loss was found in the isotope irradiation, but a definite degradative loss was seen for the reactor measurements. Although the reactor-generated 1.4 MeV He is also accompanied by a $0.85 \mathrm{MeV}$ Li ion (based on the neutron capture of ${ }^{10} \mathrm{~B}$ ) the two particles have similar LETs, and thus should be directly comparable to the isotope data. Distribution measurements showed that the distribution ratio for Am did not change with absorbed dose within the error of measurement. ESI-MS measurements on He-ion beam irradiated solutions (the only ones that did not have residual activity) showed that the main products were the amides N,N-diisobutylformamide, N-N-diisobutylacetamide and diisobutylamine formed by cleavage reactions on either side of the centratl methylene moiety of CMPO or by cleavage of the amide bond. These data have been summarized in a published journal article: Mincher, B.J.; Mezyk, S.P.; Elias, G.; Groenewold, G.S.; LaVerne, J.A.; Nilsson, M.; Pearson, J.; Schmitt, N.C., The radiation chemistry of CMPO: Part 2. Alpha radiolysis. Solv. Ext. Ion Exch., 32, 167-178, (2014).

The discrepancy in the degradative loss G-values in the ${ }^{244} \mathrm{Cm}$ and TRIGA He ion generation data for CMPO, and the inability of the ion-beam and ${ }^{211}$ At approaches to obtain sufficiently high doses for direct comparison to these two techniques, resulted in a new standardization experiment being performed. Our system was $16 \mu \mathrm{M}$ methylene blue in water at natural $\mathrm{pH}$. The advantage to this system was that it only required $1 \mathrm{kGy}$ of dose to get measurable degradation, allowing it to be investigated by all approaches. To date, both the ion-beam and the reactor experiments have been completed. The ion-beam reproduced an earlier literature value for alpha radiolysis within experimental error, with a $G_{\alpha}$ value of $-0.065 \mu \mathrm{mol} \mathrm{J}{ }^{-1}$. However, the mixed-field TRIGA reactor values could only accurately reproduce the gamma loss $\mathrm{G}_{\gamma}$-value ($0.71 \mu \mathrm{mol} \mathrm{J^{-1 }}$ ): their deduced alpha value was significantly lower at $\mathrm{G}_{\alpha}=-0.023 \mu \mathrm{mol} \mathrm{J^{-1 }}$. We 
are still waiting on the isotope measurements to be performed at INL and in Sweden $\left({ }^{211} \mathrm{At}\right)$ at this time.

Lastly, reactor measurements have also been made for TODGA degradation in dodecane, where a concentration-dependent value of $\mathrm{G}_{\alpha}=-0.022 \mu \mathrm{mol} \mathrm{J} \mathrm{J}^{-1}(10 \mathrm{mM}$ TODGA $)$ or $\mathrm{G}_{\alpha}=-0.06 \mu \mathrm{mol}$ $\mathrm{J}^{-1}$ (100 mM TODGA). These values are in contradiction with previous literature data, showing the opposite trend for the concentration-dependence. We have just completed ion-beam irradiations of these systems, but these data have yet to be analyzed. Again, isotope experiments are being planned in the next few months. 